\title{
The Using of GIS as Part of ICZM (Integrated Coastal Zone Management) for Environmental Marketing
}

\author{
Baiq Liana Widiyanti ${ }^{a}$ \\ a Universitas Hamzanwadi, Indonesia \\ E-mail Korespondensi: leea91819@gmail.com
}

\begin{abstract}
Coastal areas are very complex areas, both in terms of the physical environment and socially humanity. This study aims to provide recommendations in theoretical spatial planning in coastal areas based on the ideality level in the concept of sustainable development by using geographic information systems (GIS). This research is a literature study by using data in the form of journals and books that discuss themes related to this. The results of the study are diagrams / schemes which are theoretical conceptual models regarding the handling of problems that occur in coastal areas and how spatial planning in the region should be.
\end{abstract}

Keywords: Coastal, Environmental, GIS, ICZM, Marketing.

How to cite (APA 6th Style):

Widiyanti, Baiq Liana. (2020). The Using of GIS as Part of ICZM (Integrated Coastal Zone Management) for Environmental Marketing, 1(1), 1-11. doi: 10.26418/uniplan.v1i1.43034

\section{INTRODUCTION}

Coastal environments are at the interface of the land and sea. They are about the most dynamic of natural environments. On one side, the coastal environments connected with the sea and influenced by waves and tides, littoral drift, cliff erosion, etc. On the other side, they influenced by land processes such as sub aerial degradation of landforms at the edge of the land, transfer of water and sediment through the rivers (Carter, 2013). Distinct ecosystems (e.g. mangroves, coral reef) associated with coastal environment.

Perhaps, the most sensitive, delicately balanced, mechanisms of the coastlines are its beaches. Beaches adjust extremely quickly to changes in wave energy levels (in days, even hours) and this energy levels may be high. Beaches also react rapidly to changes in sediment type or its supply rate. Beach is not an isolated system. The change in one area will transmitted down the shorelines to the whole succession of beaches (Mineur et al., 2012).

The economic importance of coastal environments arises from the fact that the coast is the focus of trade, industry and urban activities (K. Brown \& Tompkins, 2012). All over the world, cities, ports, oil refineries, recreational and tourism complexes, fish and shrimp farms, salt plans, coconut plantations, and others along the coast. Often, there is competition between activities and functions (Barbier et al., 2011). For instance, somebody may wish to cut down the mangroves to make way for shrimps farms or salt pan which are more profitable economics activities. But the destruction of the mangroves will have a profound adverse impact in spawning of fish, protection of the shore, and prevention of the salt water incursion into terrestrial, freshwater system. Trade-offs and compromises have made to maximize the economic benefits and minimize environmental degradation regarding the coastal resources and environments (Barbier, 2012).

Man always found it necessary to make a modification to the coastline-for harbor, navigation, food production, and even recreation. The recent technological development allows these coastal modifications to make on a massive scale, and these can cause enormous problems-for their ramification spread widely throughout the coastal system (Davidson-Arnott, Bauer, \& Houser, 2019; Kremer \& Nixon, 2012). It is here 
that knowledge of the basic mechanisms involved in coastal processes is necessary but often not used until it too late.

The coastal areas are subject to several hazards (S. Brown et al., 2014; Cheong et al., 2013; Kron, 2013; Kumar, Mahendra, Nayak, Radhakrishnan, \& Sahu, 2010), such as, storm-generated floods, pollution problems (because of the pollution in the sea which washes onshore, or pollution transferred from land through river water and sediment, or municipal sewage and industrial effluent discharged directly into the sea), or coastal erosion. Natural or man-made reasons may erode the coastal area.

As population grows and their earnings improve, there would be inevitably be a greater demand for recreational facilities on the beach which may cause the destruction of vegetation, and increased erosion through wind and waves. And it should be remember that the natural forces are almost impossible to control. How should take just try to minimize its impact of improved the habitat or the ecosystem existence.

To know the whole aspect in a coastal area, a basic knowledge of coastal geomorphology (DavidsonArnott et al., 2019; Kremer \& Nixon, 2012; Kron, 2013) needed. If coastal geomorphology is to be useful, then it must provide more than general results and predictive models. We must relate it to a specific area of coastline or others and to a specific problem associated with that coast. We must bring the general theory to life using measurements from the project area. It is only when it achieves such quantification that we will achieve accurate and relevant results. The measurements in any project will depend on the problem. Three of the basic groups of data collecting common to many investigations were environmental data, coastal processes, and coastal form.

The rapid use of resources and pollution are just some issues encountered in present day coastal zones. Unmanaged resource use can lead to the deterioration of the base of the local economy (K. Brown \& Tompkins, 2012; Clark, 2018). It faces managers and decision makers allocating these resources amongst the different user of the coastal zone. They must deal with the three physical aspects of the coastal zone, the land, water and air and the social and economic factors. As pressure increases, the need for structured management becomes more urgent. Coastal zone decision makers need to take an integrated and multidisciplinary approach to the management of the areas (Diedrich, Tintoré, \& Navinés, 2010; Garmendia et al., 2010; Hopkins, Bailly, \& Støttrup, 2011).

\section{DATA AND METHODS}

This research is a qualitative study that is a literature study. The literature study here is a literature study without empirical testing. The analysis method used is descriptive because the aim is to provide a clear description and description, aim, systematic, analytical and critical regarding the use of GIS in the coastal area design planning with the concept of ICZM. Data sources are journals and books that discuss themes related to GIS and the complexity of problems in coastal areas.

\section{RESULT AND DISCUSSION}

\subsection{The Using of Geographic Information System}

Geographic Information System or GIS is a technology for handling spatial data. Developed in recent years, it now applies them are now in any fields from a local to a global scale. The GIS is a configuration of computer hardware and software for the capture, storage and processing of spatial information, both numerical and qualitative, creating and updating maps, combining and interpreting maps; they are a revolution in map structuring, content and use. GIS can classified according to application, addressed as 
urban information system, spatial decision support system, soil information system, planning information system, land information system, etc. GIS is the combination of different procedures and methodologies of computer cartography, database management, remote sensing and computer-aided design (Fotheringham \& Rogerson, 2013).

A geographic information system (GIS) as an integrated data-base management system capable of the input, storage, retrieval, analysis, output, and display of geographic or spatially indexed data. An operational GIS comprises computer hardware and software that allow the use of data layers from a variety of sources such as the topographic map, land use, and satellite images. We observed the environmental condition through remotely sensed images. By using the SPOT, for example, the sequence of image is better to detect land cover changes.

It uses the changes in land cover as an indicator of changes in a spatial pattern. Object identification by using a different band. The use offs different wavelengths in the identification can produce clear results. To know various changes of the appearance of the dynamic object evaluation, we could observe it through multi-temporal approach (Bonham-Carter, 2014). Through this approach, we can calculate and estimate the changes in the size of every object and the rate of change for a certain period. This could be very useful for design planning of spatial pattern creation.

GIS software was used to know the various changes and its size. It can measure the position and understanding of spatial data and their location by using remote sensing images. Based on the spatial arrangement, it can do the topology on the image. It also uses GIS for processing the interpreted data, and it needs spatial data including the exact position. We can get the position and spatial arrangement from the image. Integrating remote sensing and GIS based on spatial data and the image gives the right position of all the objects. The spatial structures extracted from the images and so does the spatial analysis.

Collecting terrestrial data and sea characteristics, known as natural resources in coastal areas, can do by using remote sensing technology (Klemas, 2011). It could process all the information using the GIS. Some data about natural characteristics and resources are: suspended sediment, bathymetry of topography, turbidity, sea surface temperatures, oil spills, vegetation covered (mangroves), existence of sea grass, fisheries areas, etc. All the data collected by using remote sensing technology and processed (manipulated, analyzed and presented) as the valuable information for many design planning process and function as the decision support system in natural resources conservation and development. Valid data of geography, physic and non-physic data should support the development of SIG's data based with high accuracy.

GIS (Kerski, Demirci, \& Milson, 2013; Wheatley \& Gillings, 2013) as a tool for planning has now become accepted, and it has already made some applications in environmental management have already. With the emergence of GIS capabilities, there is now the new means whereby the manipulation, analysis and evaluation of large amounts of data is possible, it can make such that reliable decision concerning locations and development planning. The idea behind it is not to develop the new GIS software, but only to see how the developed approach can help in analysis of site searching for tourism activities at the coastal area when environmental issues concern.

\subsection{Environmental Marketing}

The social, economic, politics and high technology's changes that brings the trend become Megamarketing by Kotler (Kotler, 2011, 2012). It said that the products and new marketing program could be a success if it always followed the new strong trend at a global scale. For example, the environmental trend. It could be make opportunities and threat that hard to control but needs to monitoring and response by the companies. In tourism industrial, the trend is more like the global inference or tendency held by the market. Some factors that influenced the tourism activities (Mason, 2015), they were: labors, entrepreneurship, community, competition, governmental policy, natural resources, cultural resources, organizational leadership, and finance. 
Some experts support the ideas about the core of environmental marketing's concern. The idea about the concern of environmental marketing not only ecological, nor learn the relationship among man, organization and the natural environment, but it also learned how to test past, present and future issues of environmental friendliness, recycle ability, waste reduction, the costs associated pollution, and the price value relationship of environmentalism (Carter, 2013). There always be some pressure from the stakeholders, government, special interest group, and the consumer that always testing the daily operational activities (Clark, 2018; Kinoti, 2011).

Green Marketing or Environmental Marketing has defined as a consistency of all activities that designed the facilitation and services to fill the needs and satisfaction of people without create any negative impact for the natural environment (Katrandjiev, 2016). This description almost similar with the definition of Ecological Marketing that said positive and negative impact of marketing activities will created pollution, loss of energy resources and others (Ottman, 2017; Peattie, 2016). In old marketing strategic, from the producer point of view, there were $4 \mathrm{P}$ : place, price, product, and promotion, but from a customer point of view, there 4 point too. It is known as $4 \mathrm{C}$ : customer needs and wants, cost to the customer, convenience and communication. The goal of all (concept, trick and marketing strategic) was "total customer satisfaction" (Esaki, 2013; Singh \& Kaur, 2011). At Eco-Marketing, the goal focused on eco-design products.

Much of the recent change in the planning process is because of heightened concerns to protect habitat, ensure the survival of endangered species, promote biological diversity, provide recreation, and to balance these concerns with economic issues. The focus of management has changed to concentrate on managing ecosystems rather than focusing on specific species, to ensure ecosystem sustainability by protecting habitat and promoting biological (O'riordan, 2014; Polasky, Carpenter, Folke, \& Keeler, 2011; Raymond et al., 2010).

\subsection{Attitude Research and Evolutionary Model to Analyzing The Socio-Cultural Impact}

Sensitive problem related to the development of tourism industrial or activities was the impact of social-cultural aspects. It's including the communities perception and attitude to response the changes brought by the tourism activities. It will influence the whole aspect of their lives and the surrounding environment. The effect that they get or felt has been in positive and negative ways. It involved 7 aspect of community function: public services, health, recreational, economics, environment, participatory and the infrastructure development (Dvarskas, 2017).

All the impact of tourism activities creation process if valuated by the benefit that given to the people who lived around the tourism area or region, are more accepted when has a high benefit (Meliadou et al., 2012). Back to the basic wish of everyone, get the welfare in their life, and to get it, some people did not care if they should sacrifice the environment. That why we should take wise steps to handle the problem happened there, and best solution for it was the communities participatory in every step. They have to get involved in that acts.

The concept of participation has become important in the struggle to improve the effectiveness of both "the management of organizations" and the "management of development". Even in the environmental marketing, it need to has committed itself to adopting "a participatory management style" (Souply-Pierard \& Robert, 2017) both at a project or country management levels. Therefore, a process of institutional changes, aimed at facilitating the greater involvement of people in decision-making (Garmendia et al., 2010), and it should be in progress. The problem was how to examining ways to increase participation of beneficiaries in development initiatives, and, come under increasing pressure to "professionalism" and in particular, to address a widespread neglect of management (Lins-de-Barros, 2017; Polasky et al., 2011; Raymond et al., 2010). 


\subsection{Analysis}

This paper talk about the ICZM, so the focus of interest of this theme will talk a lot of environmental management, how we see the whole problem and try to manage it's in order to made the balance of natural environment and the human life without forget the sustainable concept for natural resources. It was environmental management. The main procedure in environmental management contains 5 steps:

1. The identification of the environmental problem(s), its related to sustainable development;

2. The identification of the working forces (dominant and determinant environmental variables related to the problems);

3. The identification of the working process (the mechanism of the interaction);

4. Identification of the impacts (the positive and negative impacts).

5. The identification and formulation of the solutions (in the form of preventive, curative, innovative/developmental in the short-term program, medium-term program or long-term program).

Based on the first steps above, how to identification of the environmental problems related to sustainable development at the specific place, we should have the local knowledge about the characteristics (both natural and artificial) of that area. It could use the landscape ecology approach because one of the main goals of landscape ecology is to study the structure of the spatial mosaic and its effect on the ecological processes. Organism, energy, and resources distributed patchily in the environment. This distribution is important for most ecological patterns and processes. Complex mosaic crossed by the organism, energy, nutrient, water and disturbance processes. These elements influence by landscape heterogeneity.

We should arrange all the landscape ecology elements and their aspects into special spatial pattern that could give the best advantage for all, environment and human life. It needs a good management method application to get the best result for environmental marketing. The final aim just to get the balance between human and the environment around them as wished in sustainable development concept. It could see at the figure below about the conceptual framework. 


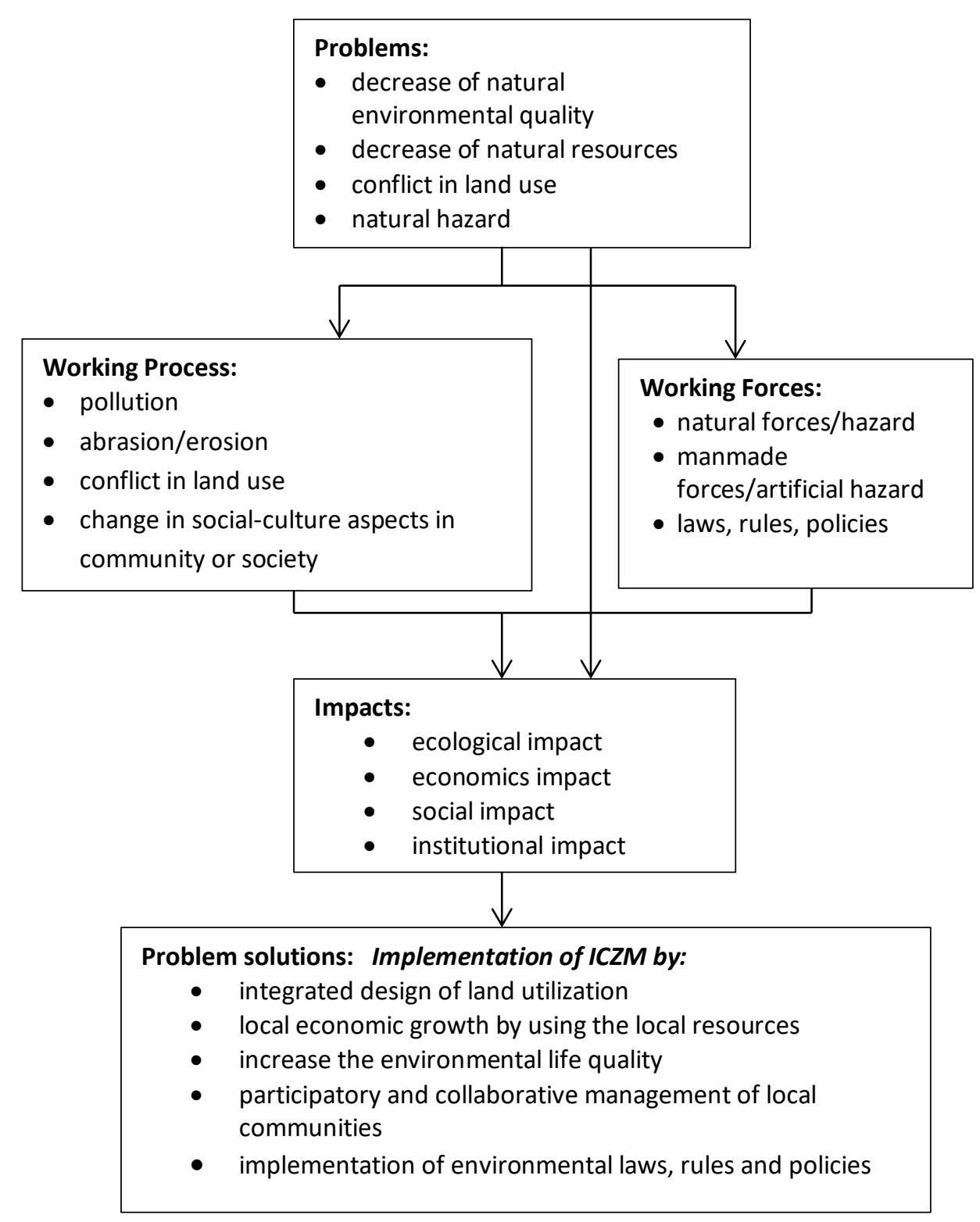

Figure 1. Conceptual Framework of Using GIS as a Part of ICZM (Integrated Coastal Zone Management) for Environmental Marketing 


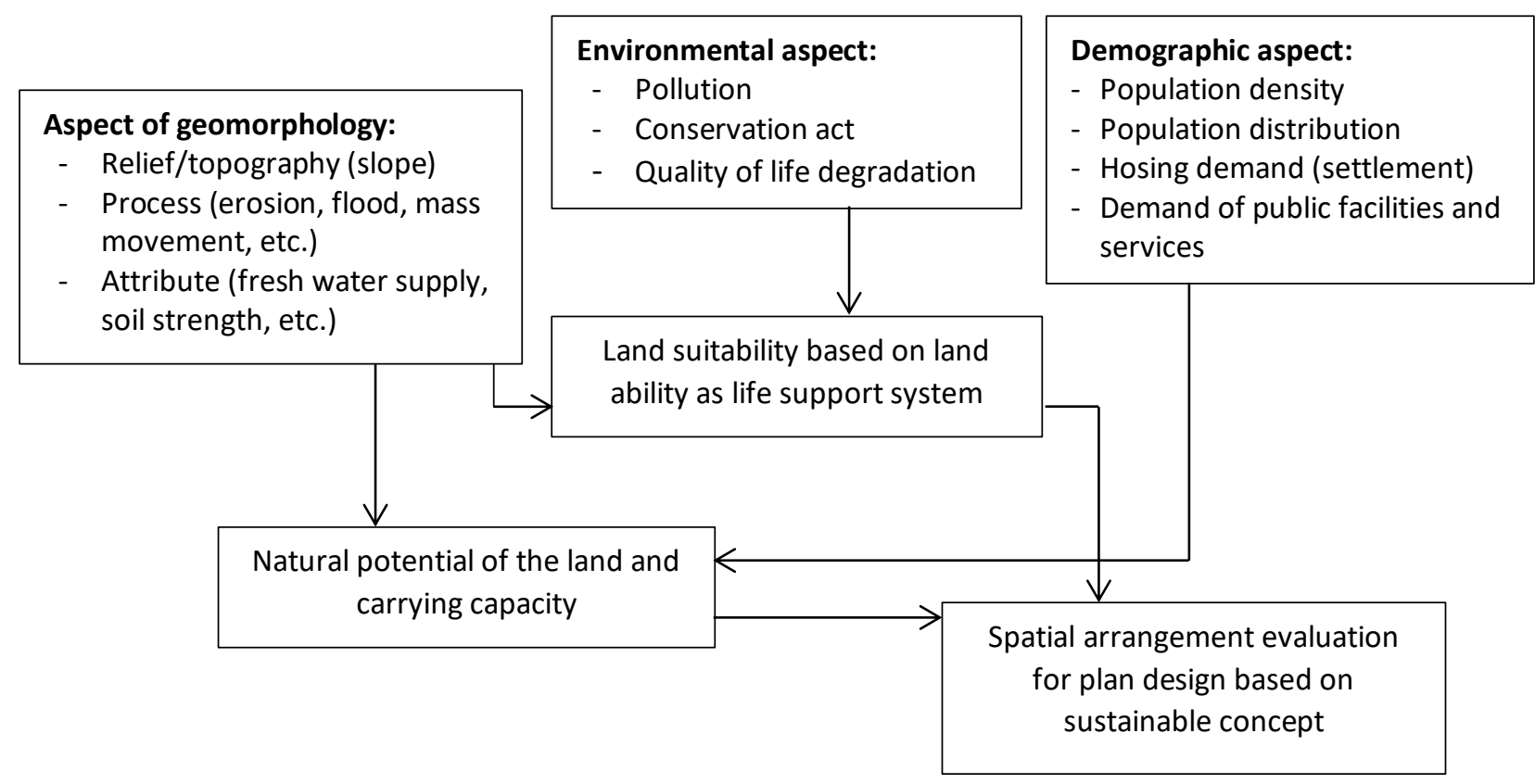

Figure 2. Natural Resources Assessment for Landscape Evaluation in Coastal Areas Based on ICZM, GIS Use for Data Collecting, Processing and Visualization As Database to be The Material of Environmental Marketing.

As had written on Chapter IV, Point 41, World Summit Conference at Rio de Janeiro $(+10)$, Johannesburg, South Africa, 2002 (Scherr \& Gregg, 2005) Plan of Implementation, World Summit on Sustainable Development about Sustainable Tourism, the core of that plan can be describe such as to promote the develop of the sustainable tourism, increase the advantages of tourism resources for the integrated population at the local community and gave a contribution to the village's strength and the local communities. It could take some steps to get the aims: (a) built the international teamwork and partnership among public and private sectors, (b) pushed the communities participatory for ecotourism, (c) increased the entrepreneurship, (d) decrease the negative impact and risk for the tradition, culture and environment, (e) promoted, increased and save the middle and lower economic groups. To reach the aims, this paper would like to take focus on activities in a coastal area for "clean industry" activities that need right and integrated strategies, especially by support the sustainable entrepreneurship in ecotourism and make application of environmental marketing as the best strategy to develop the ecotourism industries. 


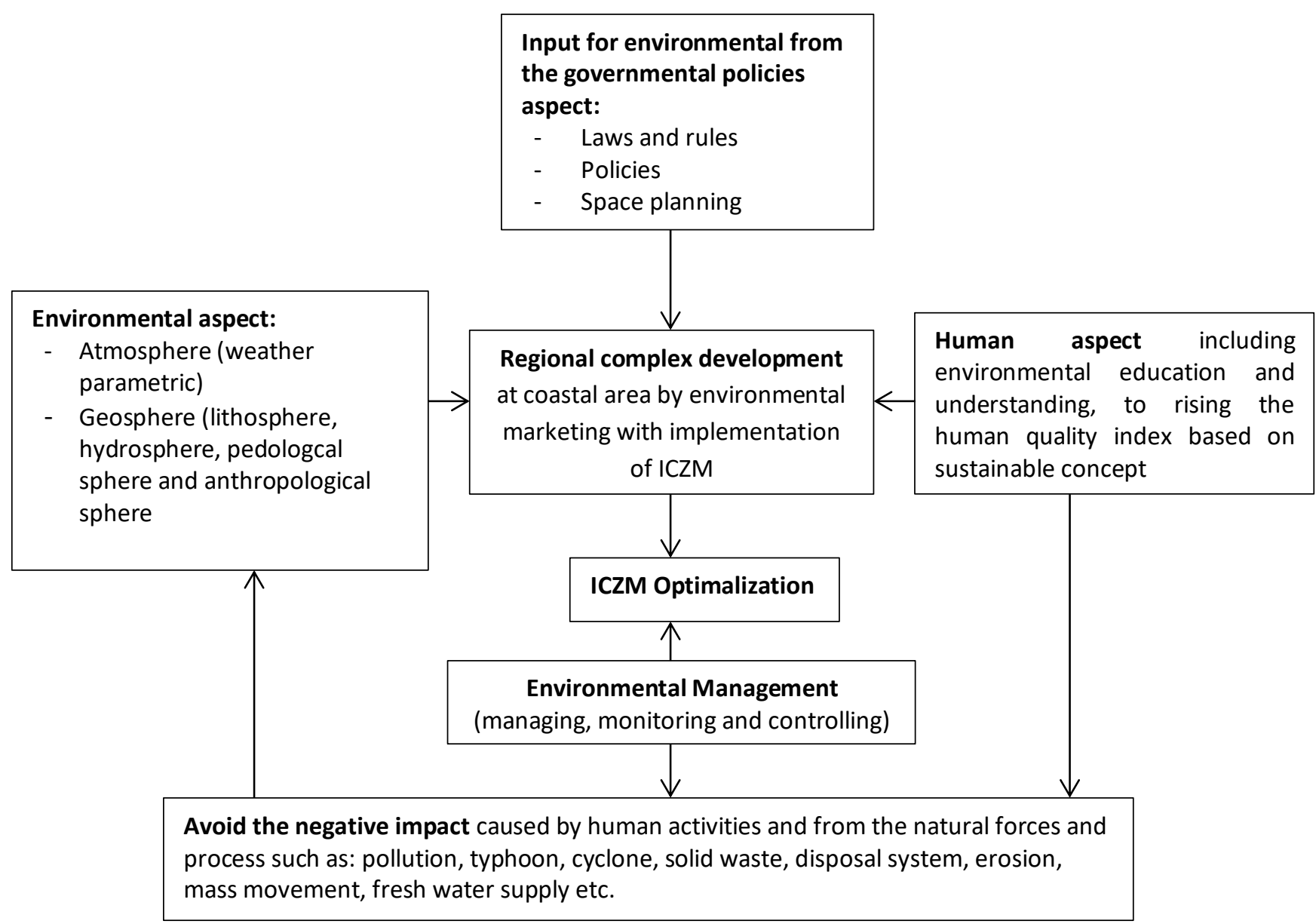

Figure 3. Scheme of Scenario

There was 5 basic factors based on the term Ecotourism (Blamey, 2001; Choy \& Heilbron, 1997; Fennell, 2007) environmental, community/society, education, experience/adventure. Ecotourism Research Group (Litvin, 1996), defined the meaning of tourism based on natural and cultural environment linked with: (1) give the education about the function and advantage of environment, (2) increasing the understanding of environmental concept, (3) useful in ecological, economic and social ways (4) give the contribution for sustainable concept, directly. Ecotourism did not a synonym with natural environmental tourism because not everything that labelled natural environmental tourism gave the positive contribution for natural conservation acts to support the sustainable development based on environmental design. Kind of that tourism activities needs special requirements if want to be call it Ecotourism and it has the special market segment (Aryanto \& Mardjuka, 2005). 


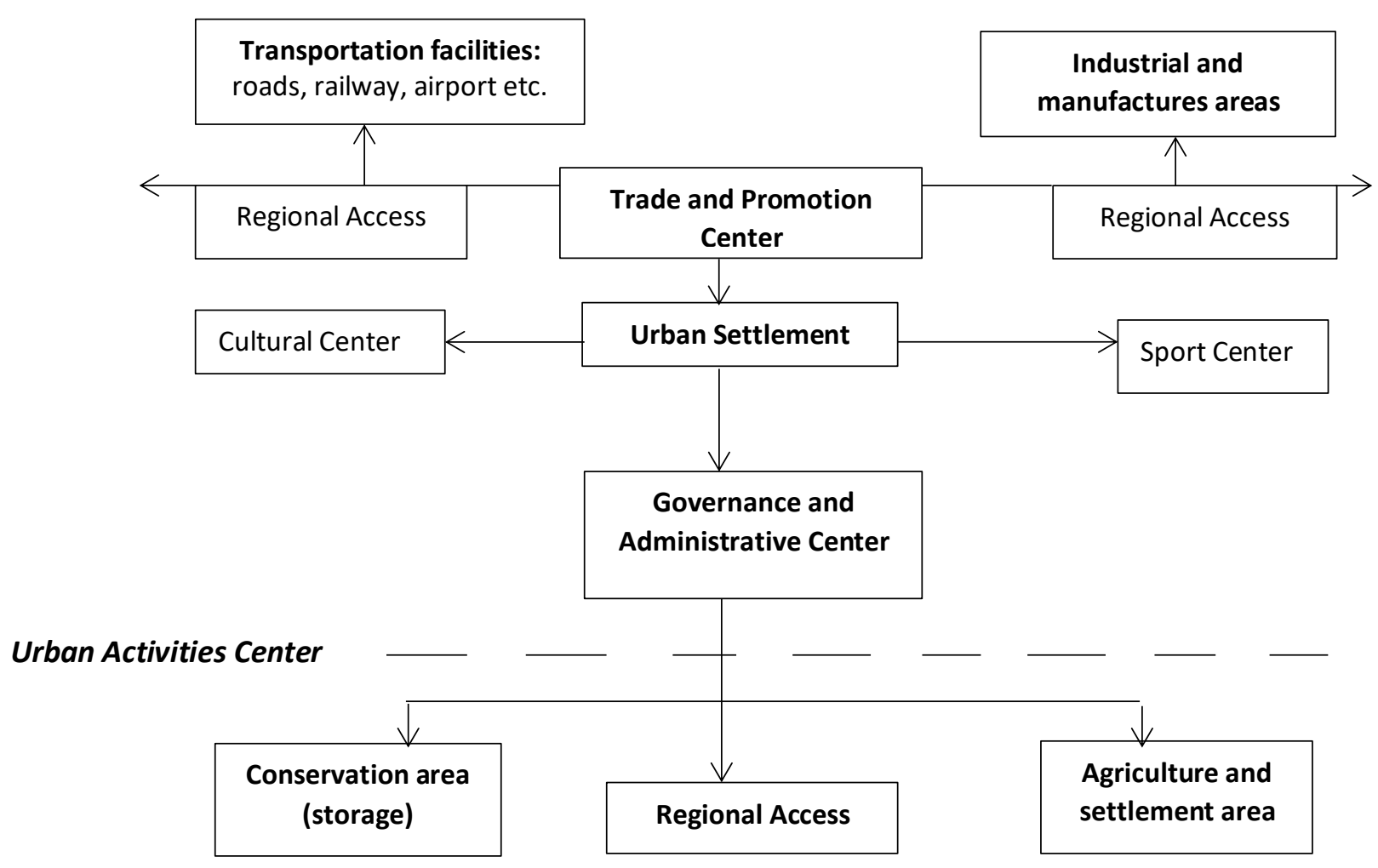

Figure 4. Space Plan Design for a Coastal Area

\section{CONCLUSION}

The need for an integration model to manage the coastal area caused by the urgent necessity to make environmental choices. The complexity of environmental problems implies that there is a growing quantity of spatially referenced information to consider and an increasing number of factors that can and dealing with such complex problems. This is where integrating different techniques/methods, different data such as remote sensing imagery data and spatial analysis by using the GIS can provide great help in understanding, examining and managing environmental problems and, hopefully, in leading to the final decision to get the highest beneficiaries from what we called Environmental Marketing. To get the best result of environmental marketing, integrating the governance, private sectors and participatory management from the local communities should create to reaches the main goal of all, welfare and wealth.

\section{ACKNOWLEDGMENTS}

Thank you to my discussion friends who always provide new ideas for writing and researching.

\section{REFERENCES}

Aryanto, R., \& Mardjuka, M. Y. (2005). Valuasi Ekonomi dengan Travel Cost Method pada Obyek Ekowisata Pesisir. Jurnal Ilmiah Pariwisata, 10(1), 58-76.

Barbier, E. B. (2012). Progress and challenges in valuing coastal and marine ecosystem services. Review of Environmental Economics and Policy, 6(1), 1-19.

Barbier, E. B., Hacker, S. D., Kennedy, C., Koch, E. W., Stier, A. C., \& Silliman, B. R. (2011). The value of estuarine and coastal ecosystem services. Ecological Monographs, 81(2), 169-193.

Blamey, R. K. (2001). Principles of ecotourism. The Encyclopedia of Ecotourism, 2001, 5-22. 
Bonham-Carter, G. F. (2014). Geographic information systems for geoscientists: modelling with GIS (Vol. 13). Elsevier.

Brown, K., \& Tompkins, E. L. (2012). Making waves: integrating coastal conservation and development. Routledge.

Brown, S., Nicholls, R. J., Hanson, S., Brundrit, G., Dearing, J. A., Dickson, M. E., ... Hinkel, J. (2014). Shifting perspectives on coastal impacts and adaptation. Nature Climate Change, 4(9), 752.

Carter, R. W. G. (2013). Coastal environments: an introduction to the physical, ecological, and cultural systems of coastlines. Elsevier.

Cheong, S.-M., Silliman, B., Wong, P. P., Van Wesenbeeck, B., Kim, C.-K., \& Guannel, G. (2013). Coastal adaptation with ecological engineering. Nature Climate Change, 3(9), 787-791.

Choy, D. L., \& Heilbron, M. (1997). Eco-tourism Planning: Lessons from South East Queensland Experience. Planning Sustainable Tourism in Balancing Tourism and Natural Resources in Economic Development, 168-178.

Clark, J. R. (2018). Coastal zone management handbook. CRC press.

Davidson-Arnott, R., Bauer, B., \& Houser, C. (2019). Introduction to coastal processes and geomorphology. Cambridge University Press.

Diedrich, A., Tintoré, J., \& Navinés, F. (2010). Balancing science and society through establishing indicators for integrated coastal zone management in the Balearic Islands. Marine Policy, 34(4), 772-781.

Esaki, K. (2013). Prediction models for total customer satisfaction based on the ISO/IEC9126 System quality model. American Journal of Operations Research, 3(04), 393.

Fennell, D. A. (2007). Ecotourism. Routledge.

Fotheringham, S., \& Rogerson, P. (2013). Spatial analysis and GIS. CRC Press.

Garmendia, E., Gamboa, G., Franco, J., Garmendia, J. M., Liria, P., \& Olazabal, M. (2010). Social multi-criteria evaluation as a decision support tool for integrated coastal zone management. Ocean \& Coastal Management, 53(7), 385-403.

Hopkins, T. S., Bailly, D., \& Støttrup, J. G. (2011). A systems approach framework for coastal zones. Ecology and Society, 16(4).

Katrandjiev, H. (2016). Ecological marketing, green marketing, sustainable marketing: synonyms or an evolution of ideas. Economic Alternatives, 1(7), 71-82.

Kerski, J. J., Demirci, A., \& Milson, A. J. (2013). The global landscape of GIS in secondary education. Journal of Geography, 112(6), 232-247.

Kinoti, M. W. (2011). Green marketing intervention strategies and sustainable development: A conceptual paper. International Journal of Business and Social Science, 2(23).

Klemas, V. (2011). Remote sensing techniques for studying coastal ecosystems: An overview. Journal of Coastal Research, 27(1), 2-17.

Kotler, P. (2011). Philip Kotler's contributions to marketing theory and practice. Review of Marketing Research: Special Issue-Marketing Legends, 8, 87-120.

Kotler, P. (2012). Kotler on marketing. Simon and Schuster.

Kremer, J. N., \& Nixon, S. W. (2012). A coastal marine ecosystem: simulation and analysis (Vol. 24). Springer Science \& Business Media.

Kron, W. (2013). Coasts: the high-risk areas of the world. Natural Hazards, 66(3), 1363-1382.

Kumar, T. S., Mahendra, R. S., Nayak, S., Radhakrishnan, K., \& Sahu, K. C. (2010). Coastal vulnerability assessment for Orissa State, east coast of India. Journal of Coastal Research, 523-534.

Litvin, S. W. (1996). Ecotourism: A study of purchase proclivity. Journal of Vacation Marketing, 3(1), 43-54.

Mason, P. (2015). Tourism impacts, planning and management. Routledge.

Mineur, F., Cook, E. J., Minchin, D., Bohn, K., MacLeod, A., \& Maggs, C. A. (2012). Changing coasts: Marine aliens and arti cial structures. In Oceanography and marine biology (pp. 198-243). CRC Press.

O'riordan, T. (2014). Environmental science for environmental management. Routledge.

Ottman, J. (2017). The new rules of green marketing: Strategies, tools, and inspiration for sustainable branding. Routledge. 
Peattie, K. (2016). Green marketing. In The marketing book (pp. 595-619). Routledge.

Polasky, S., Carpenter, S. R., Folke, C., \& Keeler, B. (2011). Decision-making under great uncertainty: environmental management in an era of global change. Trends in Ecology \& Evolution, 26(8), 398-404.

Raymond, C. M., Fazey, I., Reed, M. S., Stringer, L. C., Robinson, G. M., \& Evely, A. C. (2010). Integrating local and scientific knowledge for environmental management. Journal of Environmental Management, 91(8), 1766-1777.

Scherr, S. J., \& Gregg, R. J. (2005). Johannesburg and beyond: the 2002 World Summit on Sustainable Development and the rise of partnership. Geo. Int'l Envtl. L. Rev., 18, 425.

Singh, J., \& Kaur, G. (2011). Customer satisfaction and universal banks: an empirical study. International Journal of Commerce and Management.

Wheatley, D., \& Gillings, M. (2013). Spatial technology and archaeology: the archaeological applications of GIS. CRC Press. 